\title{
Is Education Related to Productivity?
}

Angela Little

. . . education is the principal instrument for providing the skills required by the economy and also for improving the overall levels of efficiency, productivity, technological and managerial performance of the labour force.

Five Year Development Plan, Republic of Ghana, 1977

The contribution of education to development is obvious. It shows itself in the formation of qualified individuals; in the ability of a people to absorb and produce technological innovations and raise the level of productivity on the job...

Luis Echeverria, President of Mexico, 1973

. . when it is considered how much more competently any job could be done with a little more education than a little less, educated youth are a national asset in whatever numbers they exist.

J. E. Jayasuriya, Professor of Education, Sri Lanka, 1964

That education is related to productivity is a truism so apparently self evident that few have thought to question it. The influence of human capital theory on education and manpower planners throughout the 1960 s and 1970 s in all corners of the globe perpetuated (and perhaps even created) the belief that more education will lead to increased productivity. It is not surprising that the practitioners perpetuate the belief when the theorists rarely question it. The theoretical debate of the mid-1970s focused on the question 'why is it that the educated earn more?'. Blaug, Wiles, Dore, Bowles, Gintis, Simmons, Psacharopoulos and Carnoy all contributed to the argument, some putting their money on the cognitive skills investment which education provides, some on the social skills investment, and others on the 'screening' or 'filtering' role which education plays in sifting out either those with native cognitive skills or those with native social attributes. In their formulations, all equated the question 'why do the educated earn more', with 'why are the educated more productive?'. In other words, they took for granted that the educated are more productive.
While the debate continued however, scattered research findings were emerging which questioned the assumed relationship between education and productivity. Up to the 1970 s, productivity had always been measured in terms of income, but since salaries and wages are so dependent on educational qualifications and age (particularly in the public sector) it seemed circular or unenlightening to argue that the more educated were more productive. In the early 1970 s, Berg amassed a number of studies suggesting that people with fewer years of formal school education performed no worse and sometimes even better than fellow workers with more education [1973]. He looked at the relationship within several different occupations in the USA, eg between piecework earnings and years spent at school for 585 female textile workers; between 500 bank clerks' loss of accounts and educational qualifications; between research managers' estimates of their research scientists' performance and potential and their qualifications. The major contribution of Berg's work was to employ measures of productivity other than earningsand where he did use earnings it was piecework earnings, arguably the form of payment most closely related to productivity.

In his study of the research scientists, he collected not only productivity data but also salary data. In some cases management appeared to pay according to qualifications rather than performance, eg men with masters degrees who were rated by management as 'very valuable' were paid an average salary $\$ 1,000$ lower than that paid to some with doctorates who were reportedly 'less valuable'.

Chaudhri [1974] examined the relationship between education and the productivity of farmers, measured by gross value of yield of crop per acre at state, district and household levels of analysis for India. At the household level in Uttar Pradesh, farmers with no education f requently had yields higher than those with more education. In another Indian study, Fuller [1972] compared company efficiency ratings for workers in two modern industries. In one factory there was no relationship between the number of years spent in formal school education and efficiency ratings, while in the other there was a small posi- 
tive relationship. From Kenya, Godfrey [1977] related the formal educational qualifications of candidates for government trade tests in engineering, woodworking, building, electrical skills and tailoring to their performance on those tests. His data illustrated the 'small significance of schooling in explaining test performance' and reinforce "widespread doubts about the relevance of what is learned in school to the jobs that most people end up doing' [1977: 35]. ${ }^{1}$

During the IDS Education Project on Employers Use of Educational Qualifications in Labour Markets research was designed and carried out on the relationship between educational qualifications and productivity in modern sector enterprises in Ghana, Mexico and Sri Lanka. ${ }^{2}$

In Ghana the relationship between education and productivity was examined for 19 groups of clerical workers; in Mexico for 10 different work groups ranging from security guards and salesmen to computer programmers and public relations officers; and in Sri Lanka for 9 managerial level workgroups and 9 clerical level workgroups. Our measure of productivity was the supervisor's estimate. Supervisors were asked to describe the job carried out by his/her subordinates in detail and to define the qualities of subordinates considered necessary for low and high productivity, using their own rather than external, imposed and alien criteria. After rating subordinates on different criteria, supervisors were asked to give an overall rating of performance. This was used as the measure of productivity. At no time during or preceding the ranking procedure were supervisors given any hint that this was a study of the relationship between education and producivity. Education data on the subordinates were collected later from files along with information on previous work experience, years with the firm etc. The number of subordinates per supervisor, though generally small, was in most cases large enough for meaningful statistical analysis. The range in years of education between people doing the same job for the same supervisor averaged 6.2 years in Ghana and Mexico and 3.9 years in Sri Lanka, in all cases a significant proportion of the maximum education cycle.

\footnotetext{
1 For a further brief review of the link between productivity in the 'informal sector' and education, see Callaway [forthcoming].

2 The research data in Ghana was collected by Salina Adjebey, and Kof Agyeman: in Mexico by Nigel Brooke; in Sri Lanka by Mahinda Perera and Byron Mook. The individual country studies are reported in full in Brooke et al [1978] and Deraniyagala et al [1978], the methodology in Dore et al [1975] and literature and methodological reviews in Little [1977] and Little [1974].
}

\section{Results}

Table 1 shows the correlation between educational level and productivity for the 47 workgroups along with some basic data for each workgroup. Column 1 describes the type of work performed by the members of the workgroup, column 2 whether the enterprise is from the private sector or the government sector (government corporations are classified as government), column 3 lists the number of subordinates in each workgroup, column 4 the range in years of educational levels of the subordinates, and column 5 shows the rank correlation (Kendall) between the education level and productivity measure.

This table shows there is no consistent positive relationship between level of education and productivity for a variety of different types of work. Certainly there are a few strong positive relationships, eg the group of Mexican Government Public Relations Officers and one group of private sector clerks in Sri Lanka, but the size of coefficients ranges from +0.71 all the way through to -0.89 . The average size of correlation for all 47 workgroups combined is +0.023 . Of the correlations which do reach statistical significance, four are negative and only two positive. The contribution of education to enhanced levels of productivity is by no means 'obvious'.

The simple correlation between education and productivity which we have presented in column 5 of Table 1 does not however tell us immediately whether there is or is not a real connection. Real correlations between two variables are often disguised because of the confounding effects of other variables. One might expect, for example, that experience on the job would correlate positively with productivity, but that experience would correlate negatively with education, particularly in times of rapid educational expansion and qualification escalation. If experience did correlate positively with job performance and negatively with education, then any real correlation between education and productivity would be disguised. It is necessary therefore to compute a partial correlation, ie the correlation between education and productivity, holding experience constant. Partial correlations were computed for 45 of the 47 workgroups (in the remaining two, data on experience was not available). The partial correlations are shown in column 6 of Table 1 . They too demonstrate the lack of a consistent, positive relationship between education and productivity. The partials range from +0.86 to -0.94 , the average size of coefficient being $0.05 .^{3}$

\footnotetext{
3 The partials must be treated with caution since sample sizes are very small.
} 


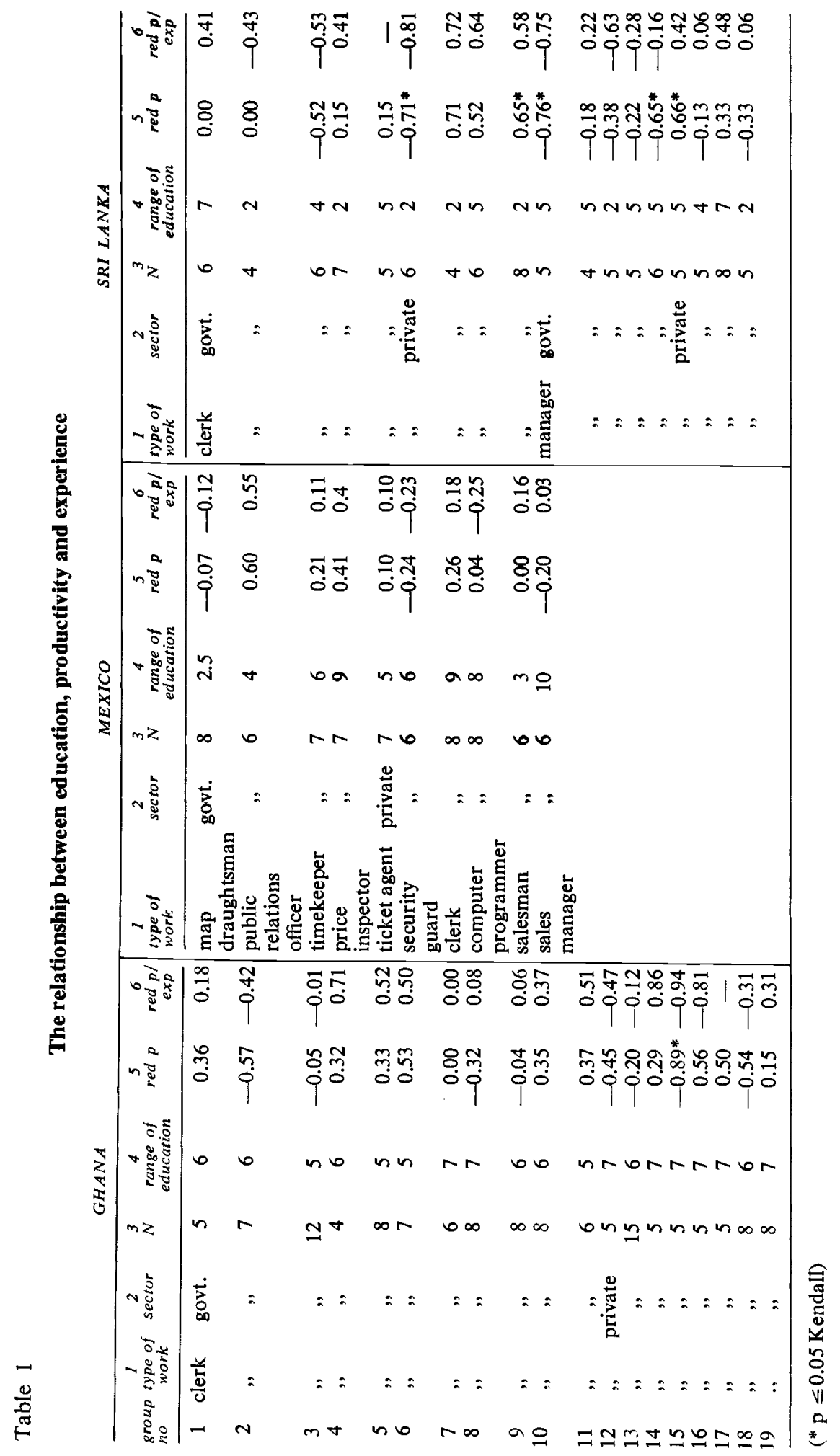


We should point out that we have not proved that education contributes nothing to productivity. To claim that would be absurd. First, we have been dealing with a restricted range of education levels. In all three countries every member of every workgroup had completed at least primary level education. In no case were we dealing with people who had either minimal or no education. Second, we have been examining a particular range of jobs - clerks, managers, public relations officers, security guards, etc. Third, we have been examining the relationship between education and productivity within particular levels of job. We have not been examining the relationship across different levels of job. Indeed to examine the relationship between education and productivity across a range of jobs in an economy (in terms other than of income) would appear to be a practical (though perhaps not a theoretical) impossibility. How does one compare the real productivity of a clerk with that of a turner or a personnel manager or a shopkeeper?

Fourth, we have concentrated on the individual characteristics of education and experience and examined these in relation to productivity. In so doing, we have ignored the effects on productivity of factors external to the individual, which may vary between individuals either in degree or in the way they interact. Take the example of clerks. Although six clerks may be performing very similar work tasks, office space constraints may require that two pairs share desks while the remaining two clerks have a desk each. Productivity differences may simply be related to the amount of space one controls. On the other hand, six clerks may appear to be working under very similar space conditions-a bustling, active, openplan office. Some clerks may find that this atmosphere suits them, others may find it distracting and would prefer the seclusion and privacy of a smaller room. Individual productivity should not be viewed simply as a product of an individual's past experience and education.

Nevertheless, we ought to point out that the range of jobs we examined ran from security guard through to manager, and covered a large proportion of occupational roles in the modern wage sector. Our finding of a lack of consistent

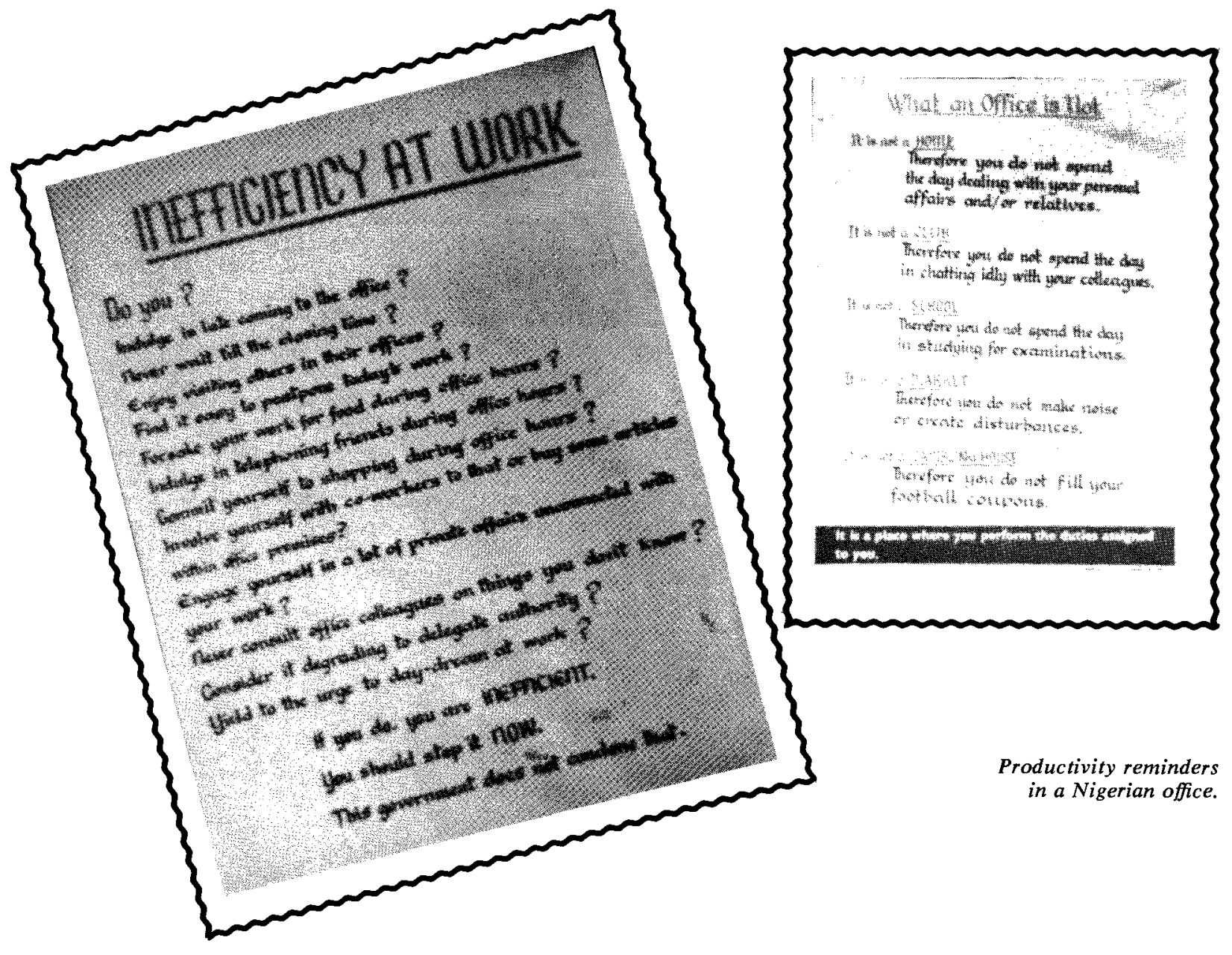


relationship between education and productivity suggests that no matter what job we choose to study, our chances of finding a strong positive relationship between educational level and productivity for a particular job would be low. The findings also suggest that the assumption made by many manpower planners that there are certain levels of education below which jobs cannot be adequately performed should be questioned.

So how do we explain our almost chance relationship between education and productivity? In answering this question let us first diverge a little and examine more of our research data. After giving a description of the job being performed by his/her subordinates, each supervisor was asked to describe the qualities/skills necessary to perform a job well. One example taken at random from the Sri Lankan data for clerks reads: loyalty, punctuality, good relations with peers, technical knowledge. We divided all the statements made by supervisors into one of two categories:

i) cognitive skills or behaviour directly related to the job itself, eg speed, accuracy, adeptness at planning; or

ii) social/affective skills involving the person's interaction with other persons or relating to some moral quality, eg relations with peers, punctuality, obedience.

In Ghana, cognitive skills such as memory and accuracy featured low on the list of factors mentioned by supervisors of clerks. More important were punctuality, obedience and willingness to work. In Mexico supervisors mentioned the social/moral attributes more frequently than the cognitive ones. There were 56 mentions of characteristics like 'ability to supervise', 'good human relations', 'responsibility', against 38 characteristics such as 'special knowledge', 'judgement' and 'problem solving ability'. Another way of looking at the breakdown of cognitive versus social skills for the Mexican data is to look at which skills predominate for which jobs. Six of the supervisors fell into a mixed category where cognitive and social skills were mentioned about equally-sales managers, invoice clerks, security guards, public relations officers, map draughtsmen and ticket reservation agents. Three mentioned mainly social skills (salesmen, price inspectors and attendance inspectors) while only one job, computer programming, was considered to require mainly cognitive skills. The different emphasis on cognitive versus social by type of job, is borne out by the Sri Lankan data. Supervisors of the managerial groups mentioned social skills eg the ability to deal with persons, either supervisors, subordinates, colleagues or customers, more frequently than supervisors of the clerical groups who tended to emphasise cognitive skills such as accuracy and neatness.

Two points emerge from this exercise. First, supervisors give social attributes equal if not more emphasis in their perception of the qualities necessary for productivity. Secondly, the mix of cognitive and social attributes will vary according to the type of job. Now if social attributes are so important for productivity and if education level tends not to be related to productivity, then maybe education is not providing the economy with enough of the right type of social attributes at the right time. (Whether the education system should be doing so is a different question.) Alternatively if jobs are so different and constitute discrete packages of skill requirements rather than packages of a continuous nature, and if different educational levels fail to correlate with degrees of mastery of any single package or job, then perhaps the contribution of different levels of education is also discrete or non-continuous. If both work and education are indeed discrete rather than continuous in character then we would not expect there to be any positive linear relationship between the two.

This view of education as a process in which the individual develops a series of discrete skills, rather than one in which a small set of skills is learned in a cumulative and continuous fashion, contradicts the conventional wisdom and, taken to its extreme, is probably untenable. It is, however, refreshing to think about education in this way, if only occasionally, for it draws attention away from the quantitative analysis of education and labour markets, which frequently assume for example: i) that the difference between five and six years of education is the same as the difference between ten and eleven years of education; and ii) that the development of social and cognitive abilities by the school proceeds in a linear fashion, so that, the higher the level of schooling, the greater the development of a particular type of ability.

On this second point, let us take an example from the primary school and the lower secondary school. The upper grade of a primary school may offer an extension of the skills learned in the lower grades of primary school, eg spelling exercises performed on longer and more difficult words. The transition to secondary school might represent, not a continuation of exercises designed to improve one's spelling ability, but a shift away 


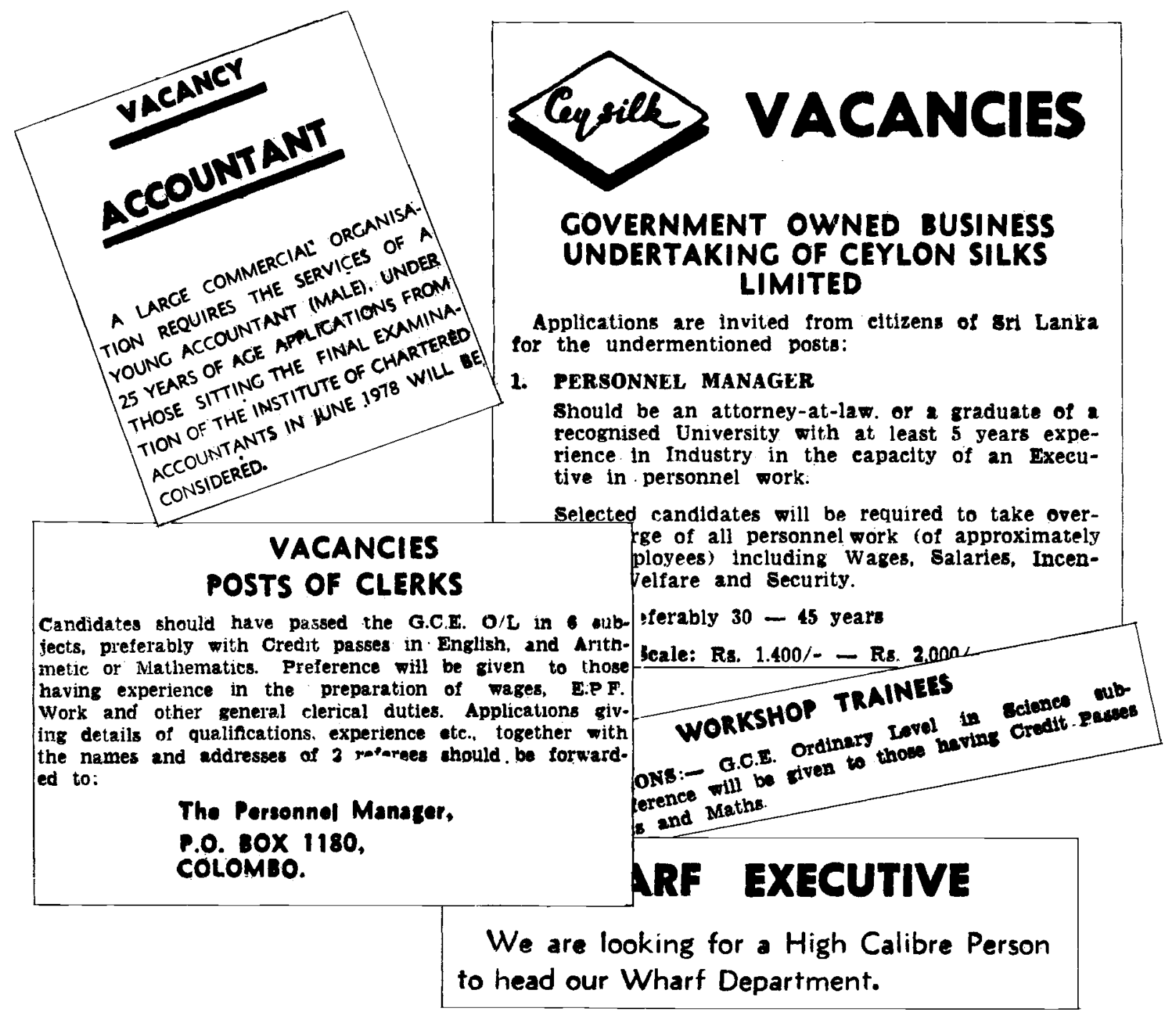

Qualifications and jobs, Ceylon Daily News, 18 June 1979.

from spelling exercises per se to using these words in writing prose, in writing poetry, in writing up a science experiment. The skills encouraged by the secondary school may indeed depend on skills learned in the primary school but there is no reason to believe that the ability to spell long words will necessarily improve with further years of schooling. Nor is there any sense in arguing that a primary school child has less mastery of the skills involved in writing up a science experiment than a secondary school child if this kind of activity does not even feature in a primary school curriculum. The analysis by Bowles and Gintis [1976] of the different social skills encouraged by the primary, secondary and tertiary levels of schooling is a good example of how to view education as a discrete rather than a continuous variable.

The problem is, of course, that a conceptual discussion about the mal-effects of different levels and types of education on productivity becomes academic when we return to social reality, and the observation that people are indeed ranked in 
society along a few continuous, linear, dimensions -level of income being the dominant one. The only explanation by those who earn more for why they do so, is that they are more educated and/or that they are productive and contribute more to society - a rationale accepted by most, and used to legitimate not only job recruitment, selection and promotion but also the escalation of qualifications, the expansion of the education system and the maintenance of wide income differentials.

For the most part, the debate about why the educated earn more seems to accept the premise that those who earn more are in fact more productive, and the debate revolves around the question 'why are the more educated more productive?'. Our research has sought to question the assumption and the implicit faith which governments around the world have in the belief that more education necessarily implies more productivity.

The main points emerging from the research are: 1 that differences in educational level (across a span of an average five years of education) appear to be unrelated to supervisors' ratings of individual productivity among groups of people doing the same job;

2 that supervisors' personal opinions about the 'ingredients' of good job performance stressed the importance of social/moral attributes for productivity on the job. The mix of cognitive versus social attributes appears to vary from job to job; 3 that if one is convinced that education really does contribute skills and attitudes which are important in the productive process and one wishes to demonstrate the connection, then a much more detailed and qualitative approach to the education variable is required-an approach which specifies and measures the precise skills and attitudes, both social and cognitive, which different levels and types of education provide. If the connections were demonstrated then perhaps manpower and educational planners might turn some of their attention away from the quantitative expansion of their education systems.

In the competition for resources, claims for the qualitative improvement of a mass primary school system are frequently ignored in face of competing claims for the quantitative expansion of secondary and tertiary systems. The claims of the opposition appeal to many. After all, the number of heads inside a classroom is easy to measure, the quality of the experience inside those heads less so.

\section{References}

Berg, I., 1973, The Great Training Robbery, Penguin

Bowles, S. and H. Gintis, 1976, Schooling in Capitalist America, Routledge and Kegan Paul

Brooke, N. et al, 1978, 'Qualifications and Employment in Mexico', IDS Research Reports 1 , IDS, Sussex

Callaway, A., forthcoming, Education for Self Employment: Africa's Indigenous Apprentice Training and its Modern Adaptations, Pergamon Press, Oxford

Chaudhri, D. P., 1974, 'Rural education and agricultural development: some empirical results from Indian agriculture' in World Year Book of Education, UNESCO, Paris

Deraniyagala, C. et al, 1978, 'Qualifications and Employment in Sri Lanka', IDS Research Reports 2, IDS, Sussex

Godfrey, M., 1977, 'Education, training and productivity: a Kenyan case study', Comparative Education Review, vol 21 no 1

Little, A., 1977, 'The Use of Educational Qualifications in Labour Markets - an Annotated Bibliography', Occasional Guides 11, IDS, Sussex

Little, A., 1974, 'Job performance and qualifications', paper presented at Study Seminar 44, IDS, Sussex, mimeo 